\title{
Intercropping of lettuce and onion controls caterpillar thread, Agrotis ípsilon major insect pest of lettuce
}

Fraide Sulvai ${ }^{1}$, Beni Jequicene Mussengue Chaúque ${ }^{1}$ and Domingos Lusitâneo Pier Macuvele $2,3^{*}$

\begin{abstract}
Background: The thread caterpillar Agrotis ipsilon (Hufnagel) (Lepidoptera: Noctuidae), is an insect pest that attacks the lettuce, Lactuca sativa and this is a serious problem faced by farmers in Niassa province due to the fact that at the end of the fourth larval stage it (insect) cuts saplings and compromising agricultural output. Usually the control of this pest has been done using synthetic insecticides, but these have environmental related implications. Thus the researches of eco-friendly forms of control have been studied.
\end{abstract}

Methods: In this research, the lettuce intercropping with onion Allium cepa was carried out to control the insect pest A. ipsilon. The experiment took place at the Agricultural Research Institute of Mozambique-IIAM. Several trials, one in monoculture (only lettuce) and other intercropped with onion were performed. In the experiment different intercropping patterns were tested, namely: Surround (a continuous line of onion surrounding a lettuce line), alternating (a line of onion and another of lettuce) and two lines of lettuce and one of lettuce.

Results: Based on tests conducted, the intercropping of lettuce with onion resulted in more plant not attacked after the test compared to the monocrop (only lettuce). In the same research we studied the best pattern to intercropping and it was found that the surrounding form (a continuous line of onion encircling a lettuce line), after the experiment, showed a higher average number of non-attacked lettuce plants.

Conclusions: Surrounding was the best intercropping pattern because showed a higher average number of nonattacked lettuce plants. The current results indicate that the onion can be used as useful tool to control the caterpillar, A. ipsolon in lettuce.

Keywords: Onion, Lettuce, Agrotis ípsolon, Intercropping

\section{Background}

The thread caterpillar Agrotis ipsilon (Hufnagel) (Lepidoptera: Noctuidae) is an insect pest that attacks around 30 important crops such as broccoli, lettuce, carrots, potatoes, beans and other crops [1]. This insect pest when in the fourth instar feeds on the leaves and in the early stages of development there is little loss of foliage, but at the end of the fourth stage they can cut many young plants in a single night [2].

\footnotetext{
*Correspondence: lusitaneom24@gmail.com

2 Department of Chemistry, Universidade Pedagógica, Branch of Niassa, 04, Campus Universitário de Chiuaula, Lichinga 04, Niassa, Mozambique Full list of author information is available at the end of the article
}

The use of synthetic insecticides is effective to control the population of $A$. ipsilion, but in recent years it has been observed Pest's resistance to some insecticides, in addition to the negative implications that come with constant use of insecticides ranging from water pollution and food contamination that can affect human health and the imbalance of the ecosystem [2]. Therefore, a pest control strategy that doesn't attack environment has been studied. The intercropping is an important cultural practice in pest management as this is to diversify crops in a given agro-ecosystem to reduce the population of insects and consequently their attack $[3,4]$. Studies indicate that intercropping protects the target plants using various mechanisms. Non-host plants involved in the mixture 
can emit volatile organic compounds which adversely affect the pest insects, giving thus some level of protection. This level of protection may involve the attraction of natural enemies of the pest insect or acts repelling the insect pest. For example, Khan et al. [5] observed that the intercropping with non-host plants such as molasses grass corn has significantly decreased the levels of infestation by stem borers and also increased larval parasitism of drills by Cotesia sesamiae. Volatile compounds produced by non-host plants repelled the insect pest, drill logs and even attracted the female parasitoid C. sesamiea. Landolt et al. [6] tested 27 essential oil extracts from 27 plants as a protective barrier against moth in fruit, and these consisted that the most effective repellents are garlic, Allium sativum L, Pogostemom cablin (Blanco) and Tanacetum vulgare $\mathrm{L}$. These results suggest that the plant or plant oils may be used as a barrier against the fruit moth.

Moreover, the simultaneous emission of volatile compounds from two or more crops in the field hinders the location host plant. Another way is the possibility of plant-plant communication where the plant can host not signal via the volatile compounds and this can protect themselves from future attacks. The other possibility is to use a plant as a sacrifice, i.e., the main mix with a plant culture, which is easily attacked by the insect pest [7].

Song et al. [8], showed that intercropping of apples orchids with three different aromatic plants ageratum (Agerarum houstonianum Mill.), French marigold (Tagetes patula L.) and basil (Ocimum basilicum L) enhanced a biological control of Aphis citricola Van der Goot. We believe that these results are related with volatiles organics compounds released by these aromatics plants.

Although there are many studies that use intercropping as a way to control insect pests but there are necessary more researches because depending on the agro-ecological, genetic variability and meteorological conditions the results may be different. So this study aims to evaluate the effect of onion Allium cepa L, Red Creno landrace in controlling thread caterpillar, dark sword-grass in lettuce by intercropping with onion in agro-ecological conditions of Lichinga.

\section{Methods}

\section{Insects}

The work was performed in Lichinga, capital town of Niassa Province, Mozambique (Fig. 1). A field was prepared in Muchenga neighborhood (where the caterpillars were identified) with a total of three plots for growing lettuce that allowed the development of caterpillars screw. This activity was carried out in this neighborhood because they already knew the basic conditions caterpillar occurrence of that neighborhood such as moisture, soil type and the type of lettuce that most appeals to A. ipsilon which is the lettuce crisp. The cultivation of lettuce was taken under natural conditions without the presence of agents that could repel and/or kill A. ipsilon.

At the time that the larvae were identified and were removed from mechanically ground and then introduced into a wooden box with similar soil in place of rearing conditions and thus transported to the test location where they were introduced in two portions.

It is important to mention that the caterpillars of $A$. ipsilon appeared in themselves creating the field, it was not necessary to lay eggs, or adult moths or larvae during this period of creation caterpillars fed on lettuce until the time of their removal.

\section{Plants}

They were prepared in two seedbeds where one contained a variety of onion (Red Creno) and the other contained a variety of lettuce (crisp head lettuce). The onion seed was conducted two weeks before the lettuce seed to coincide with the development of the two cultures, although knowledge of the onion is presenting very long life cycle as compared to lettuce.

In seedbeds, the seeds were laid in rows, and a week after germination in seedbeds of both cultures were clean (mulching) so as to eliminate the possible weeds present in them.

Seedlings of both crops were transplanted into the final installments on the same day, in the morning period this activity was carried out 3 weeks after the emergence of lettuce. Furthermore, the test site were prepared six portions distributed in two portions, the first portion was intercropped and the second was a control which had only lettuce plants.

\section{Intercropping assay}

For intercropping crop the aid was necessary from a tape-metric for measuring portions and compasses to use on these crops. The bars that were used varied with the culture; thus, for lettuce crop was used a measure $30 \mathrm{~cm}$ from one plant to another and from one line to another; for onion crop was used a compass $10 \mathrm{~cm}$ distance between a plant of another within the line.

Thus, three different forms of the consortium were used, in which the first has alternating cultures of lines (one line onions and other lettuce), the second was the toggle also cultures of lines (two lines of lettuce and onion); finally, the third way was to put a solid row of onions around the plot and lettuce plants were placed in the middle of the plot (Fig. 2).

\section{Data collection and statistical analyses}

At the end of each test, the number of intact lettuce plants were counted and attacked at the field in intercropping and control field (with only lettuce), and in the 

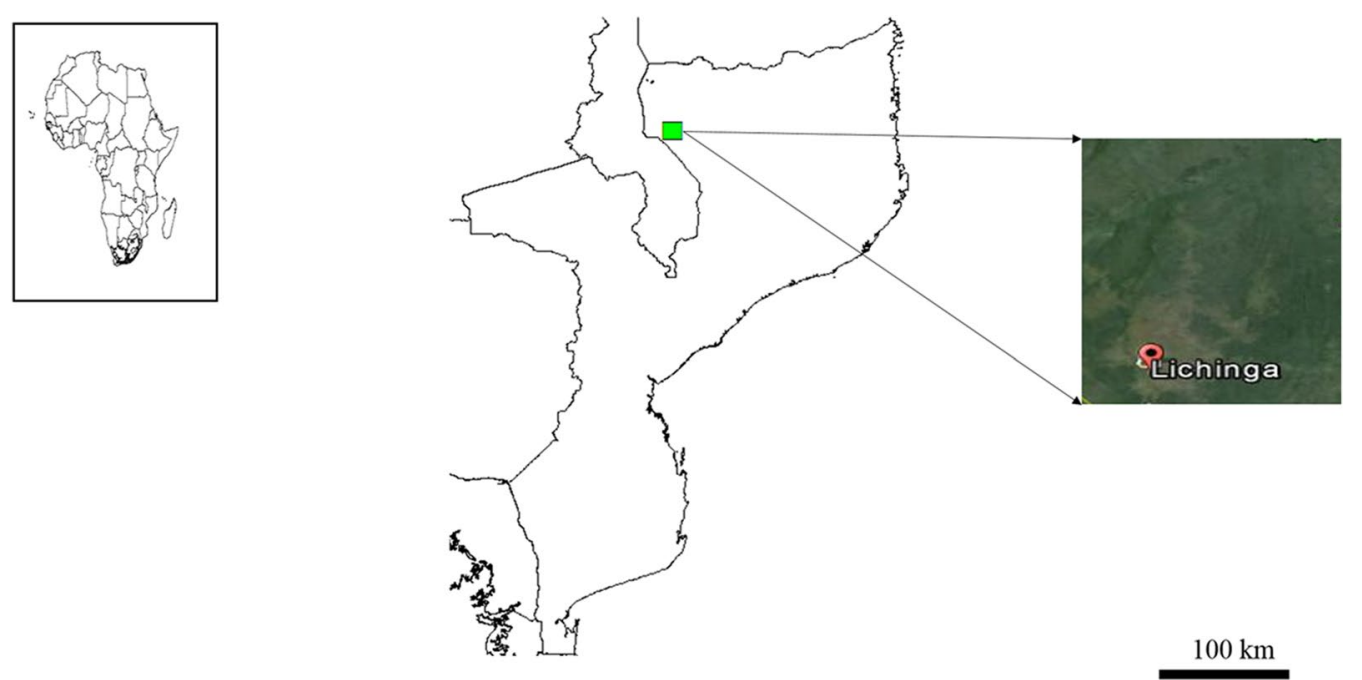

Fig. 1 Location of study area

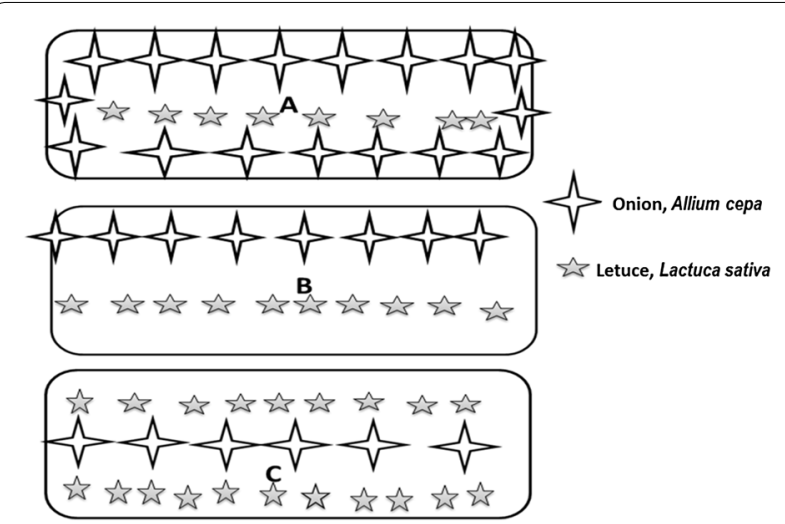

Fig. 2 Intercropping patterns: A- onion continuous line around a line of lettuce- Surround; B- a line of onion and one lettuce line $\mathbf{C}$-two rows of lettuce and one onion line

different intercropping patterns. The mean comparison was based on ANOVA followed by Tukey's test.

\section{Results}

According to the experiments, it was observed that the control field compared to the field in intercropping showed a fewer number of lettuce plants not attacked $(P<0.05)$ by the caterpillar after the test. This result can be seen in the chart below (Fig. 3).

In this experiment we also tested three patterns of intercropping, namely: continuous onion queue around the hotbed (Surround), switching crops between rows (a row of onion and other lettuce) and switching crops between rows (two lines lettuce and onion). The intercropping in Surround had significant a higher average

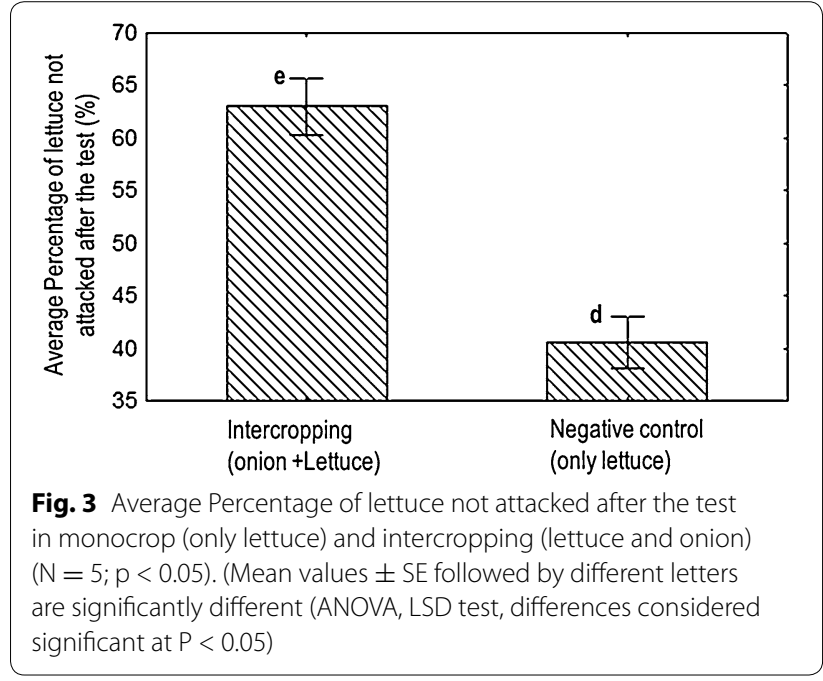

$(p<0.05)$ number of plants not attacked after testing compared with other forms of intercropping (Fig. 4 and Table 1).

\section{Discussion}

The lettuce field in monoculture showed a smaller number of plants not attacked after the test from the field in intercropping with onion. Caterpillars threads $A$. ipsolon intensely attacked the camp in monoculture leaving few plants, this observation could be attributed to the fact that insects use volatile compounds to find the hosts and this phenomenon location in monoculture fields is very easy just because the host would be a released volatile organic compounds. Moreover, it was observed that in 


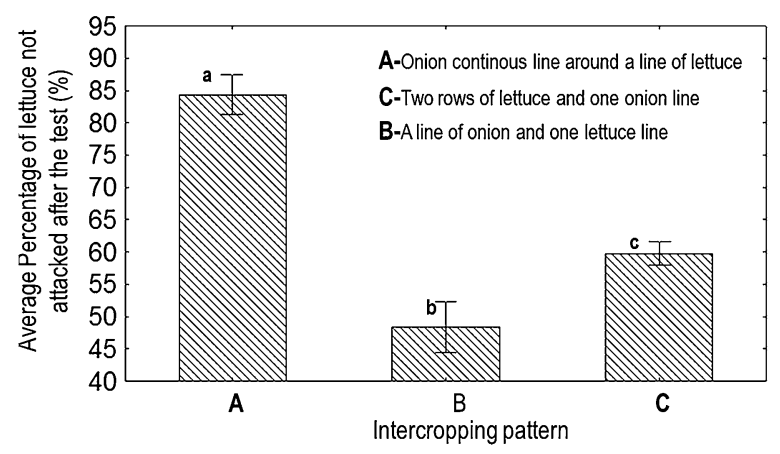

Fig. 4 Average Percentage of lettuce not attacked after the test in the various patterns of intercropping $(N=5 ; p<0.05)$. Mean values \pm SE followed by different letters are significantly different (ANOVA, LSD test, differences considered significant at $\mathrm{P}<0.05$ )

Table 1 Univariate tests of significance for average number of lettuce not attacked after the assay sigma-restricted parameterization effective hypothesis decomposition

\begin{tabular}{lrrrrl}
\hline Effect & \multicolumn{1}{l}{ SS } & DF & \multicolumn{1}{l}{ MS } & \multicolumn{1}{l}{ F } & p \\
\hline Intercept & 61714.23 & 1 & 61714.23 & 10191.28 & 0.000000 \\
Treatment & 3385.11 & 2 & 1692.56 & 279.50 & 0.000000 \\
Error & 72.67 & 12 & 6.06 & & \\
\hline
\end{tabular}

areas with mixed cultures (lettuce and onion), few plants were attacked and at the end of study many lettuce plants remained intact. The intercropping with lettuce onion has a direct effect on the caterpillars, A. ipsolon and other insects. This effect can be connected to emission of toxic volatile organic compounds or repellents $A$. ipsolon also the onion can mask volatile organic compounds released by lettuce used by insects such signals for location [9]. According Mann et al. [10], onion odor emits sulfur containing organic compounds called thiols and these substances can participate in various protective mechanisms described above. Additionally Debra and Misheck [11], obtained similar results to this study, intercropping cabbage crop with onion and garlic, observed that the death of cabbage plants and the incidence of insects significantly reduced while the yield of cabbage was higher. In another study, intercropping was made between wheat and garlic to control the grain aphid Sitobion avenae Fabricius (Homoptera: Aphididae), on the basis of experiments it was observed a reduction in the aphid population and that yields of grain wheat significantly increased [12]. Allium cepa showed to be efficient in control of aphid population while this is intercropped with collard [13].

Several studies on the effect of intercropping in the management of insects have been described in the literature and the results were similar to those found in this work [14-21].

In the same study, tree intercropping patterns were evaluated, and found that the medium surrounds presented a higher number of lettuce plants not attacked in the end of experiment in relation to other patterns. It is important to investigate various forms of intercropping, because depending on how it is made can have an additive effect in reducing the insect pest population. We believe that the border intercropping pattern was the best intercropping pattern of onion with lettuce because, first the caterpillar to enter in the field finds a barrier of onion crop and this attacks the onion, it begins to release a number of volatile organic compounds containing sulfur and these may have a defensive role. This hypothesis is congruent with Huang et al. [22], Dugravot et al. [23], Rouseff et al. [24] and Auger et al. [25], who have investigated the role of volatiles compounds released by Allium spp after damaged and those were classified as toxic or repellents for various insect pest. Mann et al. [10], observed that Sulfur volatiles from Allium spp. affect Asian citrus psyllid, Diaphorina citri Kuwayama (Hemiptera: Psyllidae), response to citrus volatiles. This behavior was linked to trisulfides (dimethyl trisulfide) and disulfides and those had inhibition response of $D$. citri.

\section{Conclusion}

Intercropping fits into environmentally acceptable and sustainable vegetable-producing practices. Based on field assays conducted, the intercropping of lettuce with onion resulted in more plant not attacked after the test compared to the monocrop (only lettuce). The surround (a continuous line encircling onion lettuce line) intercropping pattern was the best intercropping pattern because, the assay showed a higher average number of nonattacked lettuce plants compared to other patterns. The current results indicate that the onion can be used as a useful tool to control the caterpillar, A. ipsolon in lettuce.

\section{Authors' contributions}

FS developed the experimental design with supervision of BJM, DLPM and BJM offered advice during the development of the experiment, interpretation of results. Domingos Lusitâneo P. Macuvele, provided a general organization and interpretation of results and participated actively during the in manuscript writing. All the authors participated actively in this manuscript. All authors read and approved the final manscript.

\section{Author details}

${ }^{1}$ Department of Biology, Universidade Pedagógica, Branch of Niassa, 04, Lichinga 04, Niassa, Mozambique. ${ }^{2}$ Department of Chemistry, Universidade Pedagógica, Branch of Niassa, 04, Campus Universitário de Chiuaula, Lichinga 04, Niassa, Mozambique. ${ }^{3}$ Department of Chemical Engineering, Universidade Federal de Santa Catarina, Florianópolis, Brazil.

\section{Acknowledgements}

The authors are grateful for the Department of Research and Extension of Pedagogical University of Mozambique-Campus of Niassa Province. Instituto de Investigação Agrária de Moçambique (Niassa) is also acknowledged for 
providing field to conduct the assays. One of author thank the The World Academy of Sciences-Conselho Nacional para o Desenvolvimento Científico e Tecnológico (TWAS-CNPq). The authors would also like to thank reviewers for their valuable comments and suggestions.

\section{Competing interests}

The authors declare that they have no competing interests.

Received: 11 June 2016 Accepted: 11 August 2016

Published online: 26 October 2016

\section{References}

1. Boughton AJ, Lewis LC, Bonning BC. Potential of agrotis ipsilon nucleopolyhedrovirus for suppression of the black cutworm (Lepidoptera: Noctuidae) and effect of an optical brightener on virus efficacy. J Econ Entomol. 2001;94:1045-105.

2. Jeyasankar A. Antifeedant, insecticidal and growth inhibitory activities of selected plant oils on black cutworm, Agrotis ipsilon (Hufnagel)(Lepidoptera: Noctuidae). Asian Pacific Journal of Tropical Disease. 2012;2:S347-51.

3. Singh KA, Ahlawat IPS., Mahiendrapal H. Cropping Systems Research 1. Concept, Needs and Directions. Proceedings of the National Symposium on Cropping Systems, New Delhi, Indian Society of Agronomy, Indian Agricultural Research Institute. 1986.

4. Degri MM, Mailafiya DM, Mshelia JS. Effect of intercropping pattern on stem borer infestation in pearl millet (Pennisetum glaucum L.) grown in the Nigerian Sudan Savannah. Adv Entomol. 2014;2:81-6,

5. Khan ZR, Chiliswa P, Ampong-Nyarko K, Smart LE, Polaszek A, Wandera J. Mulaa M.A Utilisation of wild gramineous plants for the management of cereal stemborers in Africa. Insect Sci. Appl. 1997;1997(17):143-50.

6. Landolt PJ, Hofstetter RW, Biddick LL. Plant essential oils as arrestants and repellents for neonate larvae of the codling moth (Lepidoptera: Tortricidae). Environ Entomol. 1999;28:954-60.

7. Parker JE, Rodriguez-Saona C, Hamilton GC, Snyder WE.Companion planting and insect pest control. INTECH Open Access Publisher.2013.

8. Song B, Tang G, Sang X, Zhang J, Yao Y, Wiggins N. Intercropping with aromatic plants hindered the occurrence of Aphis citricola in an apple orchard system by shifting predator-prey abundances. Biocontrol Sci Technol. 2013;23:381-95.

9. Pahla I,Tumbare T, Chitamba J, Kapenzi A. Evaluation of Allium sativum and Allium cepa intercrops on the control of Brevicoryne brassicae (Homoptera: Aphididae) in Brassica napus. 2014; 2:1069-74.

10. Mann RS, Mann RS, Rouseff RL, Rouseff RL, Smoot JM, Castle WS, Stelinski LL. Sulfur volatiles from Allium spp. affect Asian citrus psyllid, Diaphorina citri Kuwayama (Hemiptera: Psyllidae), response to citrus volatiles. Bull Entomol Res. 2011;101:89-97.

11. Debra, K. R., and Misheck, D. Onion (Allium cepa) and garlic (Allium sativum) as pest control intercrops in cabbage based intercrop systems in Zimbabwe.ISO 690
12. Zhou HB, Chen JL, Yong LIU, Francis F, Haubruge E, Bragard C, Sun J, Cheng DF. Influence of garlic intercropping or active emitted volatiles in releasers on aphid and related beneficial in wheat fields in China. J Integr Agric. 2013;12:467-73.

13. Saidi M, Itulya FM. Effect of intercropping collard with beans or onions on aphid populations and yields of collard under high altitude conditions in Kenya. Tanzania J Agric Sci. 2006;7:56-66.

14. Vaiyapuri K, Amanullah MM, Rajendran K, Sathyamoorthi K. Intercropping unconventional green manures in cotton: an organic approach for multiple benefits: a review. Asian J Plant Sci. 2010;9:223-6.

15. Wang WL, Liu Y, Ji XL, Wang G, Zhou HB. Effects of wheat-oilseed rape intercropping or wheat-garlic intercropping on population dynamics of Sitobion avenae and its main natural enemies. Chin J Appl Ecol. 2008;19:1331-6.

16. Wang WL, Liu Y, Chen JL, Ji XL, Zhou HB, Wang G. Impact of intercropping aphid-resistant wheat cultivars with oilseed rape on wheat aphid (Sitobion avenae) and its natural enemies. Acta Ecologica Sinica. 2009:29:186-91.

17. Zhang L, van der WerfW, Zhang S, Li B, Spiertz JHJ. Growth, yield and quality of wheat and cotton in relay strip intercropping systems. Field Crop Res. 2007;103:178-88.

18. Cai HJ, Li SY, Ryall K, You MS, Lin S. Effects of intercropping of garlic or lettuce with Chinese cabbage on the development of larvae and pupae of diamondback moth (Plutella xylostella). Afri J Agric Res. 2011;6:3609-15.

19. Xiao X, Cheng Z, Meng H, Khan MA, Li H. Intercropping with garlic alleviated continuous cropping obstacle of cucumber in plastic tunnel. Acta Agric Scand Sect B-Soil Plant Sci. 2012;62:696-705.

20. Karavina C, Mandumbu R, Zivenge E, Munetsi T. Use of garlic (allium sativum) as a repellent crop to control diamondback moth (plutella xylostella) in cabbage (brassica oleraceae var. capitata). J. Agric. Res. 2014; 52.4

21. Jankowska B, Jedrszczyk E, Poniedzialek M. Effect of intercropping carrot (Daucus carota L.) with french marigold (Tagetes patula nana L.) and pot marigold (Calendula officinalis L.) on the occurrence of some petsts and quality of carrot yield. Acta Agrobotanica. 2012;65:133-8.

22. Huang Y, Chen SX, Ho SH. Bioactivities of methyl allyl disulfide and diallyl trisulfide from essential oil of garlic to two species of stored-product pests, Sitophilus zeamais (Coleoptera: Curculionidae) and Tribolium castaneum (Coleoptera: Tenebrionidae). J Econ Entomol. 2000;93:537-43.

23. Dugravot S, Grolleau F, Macherel D, Rochetaing A, Hue B, Stankiewicz M, Huignard J, Lapied B. Dimethyl disulfide exerts insecticidal neurotoxicity through mitochondrial dysfunction and activation of insect KATP channels. J Neurophysiol. 2003;90:259-70.

24. Rouseff RL, Onagbola EO, Smoot JM, Stelinski LL. Sulfur volatiles in guava (Psidium guajava L.) leaves: possible defense mechanism. J Agric Food Chem. 2008:56:8905-10.

25. Auger J, Lecomte C, Thibout E. Leek odour analysis by gas chromatography and identification of most active substance for leek moth Acrolepiopsis assectella. J Chem Ecol. 1989;15:1847-54.

\section{Submit your manuscript to a SpringerOpen ${ }^{\circ}$ journal and benefit from:}

- Convenient online submission

- Rigorous peer review

Immediate publication on acceptance

- Open access: articles freely available online

- High visibility within the field

- Retaining the copyright to your article

Submit your next manuscript at $>$ springeropen.com 